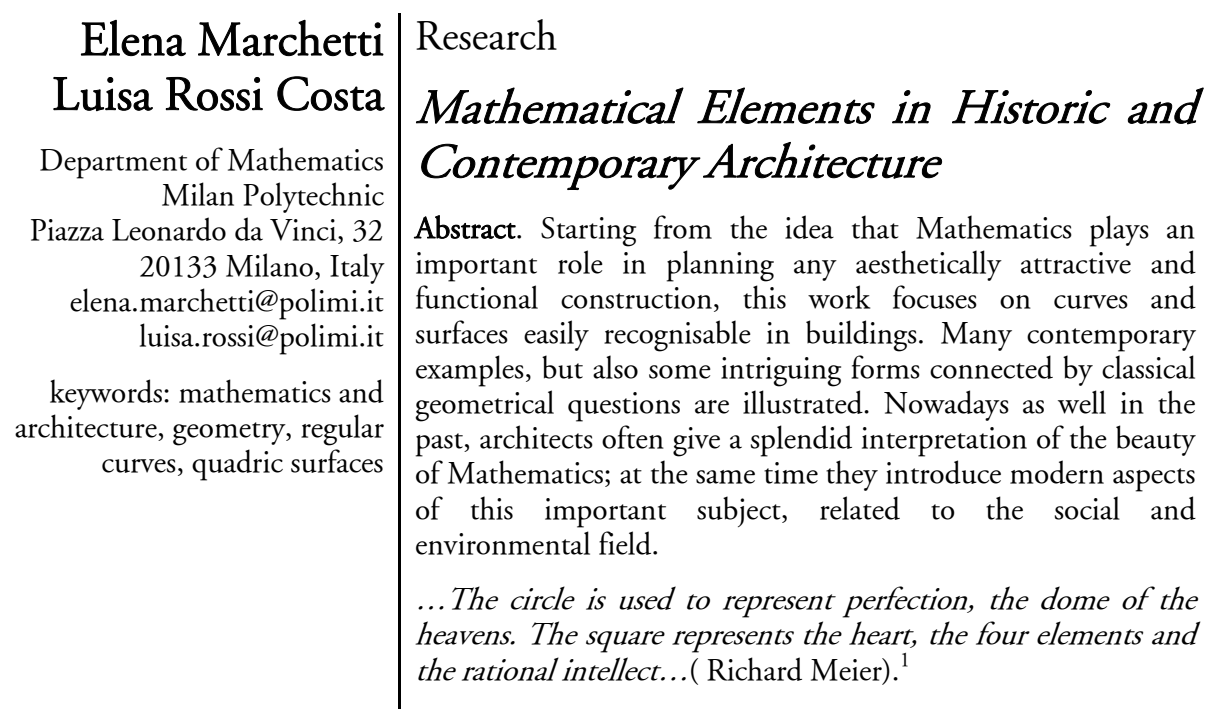

\title{
Introduction
}

The surfaces externally delimiting significant buildings and the forms characterizing their interiors are usually very elegant and well proportioned.

Some observers consider these shapes only from an artistic point of view and they appreciate principally the aesthetic aspect; others, because of their scientifictechnical background, try to understand the structural and mathematical properties as well. These last conscious that the pleasant harmony of an architectural structure comes also from its intrinsic geometrical qualities and from the structural and decorative materials employed.

Therefore as mathematicians interested in architecture and arts, we would like to confirm the fact that the shape's harmony comes not only from the artist's creativity but it is strictly connected with mathematical rules. The more you know mathematical tools the more you understand and appreciate the form's beauty.

In this paper we intend to focus on curves and surfaces often involved in façades, domes and vaults of buildings. The aim is to illustrate those forms in mathematical way, to underline their configuration and some essential particulars not always evident at first glance.

We take this occasion also to notice that the contemporary architects consider important technical aspects as well, to make buildings more functional, to minimize energy costs or to facilitate insertion in the social, environmental context. Consequently mathematics enters deeply in planning (mathematical modelling) in order to realize a better performance.

Nexus Network Journal 8 (2006) 79-92

NEXUS NETWORK JOURNAL - VOL. 8, NO. 2, 200679 
In the first section we introduce the mathematical elements used to represent curves and surfaces; in the second section we describe and generate different forms, as recognisable in classical monuments as in recent buildings, among them skyscrapers [Höweler 2004]. In the third section we present an interesting contemporary use of portions of cylinders and spherical surfaces: the elementary geometric parts are involved again but they produce a totally different effect in the buildings, thanks to the creativity of the architects.

\section{Mathematical tools}

We introduce the essential mathematical elements to describe curves and surfaces; among different possibilities we select the parametric form, one of the most adaptable and efficient way to represent the geometrical loci as graphically as well as analytically. More in detail, in the 3D Cartesian orthogonal space Oxyz, a regular curve is represented by a vector $\mathbf{v}(t)=\left[\begin{array}{c}x(t) \\ y(t) \\ z(t)\end{array}\right]$, whose components depend on the real parameter $t \in I=[a, b] \subset R, \quad \mathbf{v}(t) \in C^{1}(I)^{2} \quad$ and $\left\|\mathbf{v}^{\prime}(t)\right\|=\sqrt{x^{\prime}(t)^{2}+y^{\prime}(t)^{2}+z^{\prime}(t)^{2}} \neq 0$, that is, the usual conditions of regularity are satisfied.

A regular surface is equally represented by a vector $\mathbf{w}(t, u)=\left[\begin{array}{c}x(t, u) \\ y(t, u) \\ z(t, u)\end{array}\right]$, depending on two real parameters $(t, u) \in A=([a, b] \times[c, d]) \subset R^{2}, \quad \mathbf{w}(t, u) \in C^{1}(A) \quad$ and $\left\|\mathbf{w}_{t} \wedge \mathbf{w}_{u}\right\| \neq 0 .^{3}$

In both cases, for curves as well as for surfaces, the parameterisation is not unique.

Hereby we mention basic regular curves and choose a standard parameterisation:

\begin{tabular}{|l|l|l|}
\hline $\begin{array}{l}\text { Straight } \\
\text { line: }\end{array}$ & $\mathbf{v}(t)=\left[\begin{array}{c}x_{0}+\alpha t \\
y_{0}+\beta t \\
z_{0}+\gamma t\end{array}\right], t \in R ;$ & $\begin{array}{l}\text { the point } P_{0}=\left(x_{0}, y_{0}, z_{0}\right) \text { belongs to the line } \\
\text { having the direction of the vector }\left[\begin{array}{c}\alpha \\
\beta \\
\gamma\end{array}\right] \neq 0 .\end{array}$ \\
\hline Ellipse: & $\mathbf{v}(t)=\left[\begin{array}{c}r_{1} \cos t \\
r_{2} \sin t \\
0\end{array}\right], t \in[0,2 \pi]$ & $\begin{array}{l}\text { where } r_{1}, r_{2} \in R^{+} \text {(that is positive real numbers) } \\
\text { are the semi-axes of the ellipse centred in O and } \\
\text { belonging to the } x y \text { plane; the ellipse becomes } \\
\text { a circle if } r_{1}=r_{2} .\end{array}$ \\
\hline
\end{tabular}

80 E. MARCHETTI and L. Rossi COSTA - Mathematical Elements in Historic and Contemporary Architecture 


\begin{tabular}{|l|l|c|c|}
\hline Parabola: & $\mathbf{v}(t)=\left[\begin{array}{c}t \\
a t^{2}+b t+c \\
0\end{array}\right], t \in R$ & $\begin{array}{l}\text { and the coefficients } a, b, c \in R \text {; the parabola, } \\
\text { belonging to the } x y \text { plane, has symmetry axis } \\
\text { parallel to y-axis. }\end{array}$ \\
\hline Spiral: & $\mathbf{v}(t)=\left[\begin{array}{c}f(t) \cos t \\
f(t) \sin t \\
0\end{array}\right], t \in R$ & $\begin{array}{l}\text { where } f(t) \in C^{1}(R) \quad \text { is a nonnegative, } \\
\text { monotone function; the choice } \\
f(t)=a t, a \in R^{+}, \text {gives Archimedean spirals, } \\
\text { the choice } f(t)=e^{a t}, a \in R, \text { gives logarithmic } \\
\text { spirals. }\end{array}$ \\
\hline
\end{tabular}

We also introduce basic regular quadric surfaces such as:

\begin{tabular}{|c|c|c|c|}
\hline Ellipsoid: & $\mathbf{w}(t, u)=$ & {$\left[\begin{array}{c}a \sin t \cos u \\
b \sin t \sin u \\
c \cos t\end{array}\right]$} & $\begin{array}{l}(r, u) \in([0, \pi] \times[0,2 \pi]) \text { and } a, b, c \in R^{+} \text {; the } \\
\text { coefficients } a, b, c \text { give the semi-axes of the } \\
\text { ellipsoid, centred in } O \text {. The ellipsoid } \\
\text { becomes a sphere if } a=b=c \text {. }\end{array}$ \\
\hline $\begin{array}{l}\text { Circular } \\
\text { paraboloid: }\end{array}$ & $\mathbf{w}(t, u)=$ & {$\left[\begin{array}{c}u \cos t \\
u \sin t \\
c u^{2}\end{array}\right]$} & $\begin{array}{l}(r, u) \in\left([0,2 \pi] \times R^{+}\right) \text {and } c \in R \text {; the } z \text {-axis } \\
\text { is the symmetry rotation axis and the vertex } \\
\text { is placed in } O \text {. }\end{array}$ \\
\hline Cylinder: & $\mathbf{w}(t, u)=$ & $\left.\begin{array}{c}a \cos t \\
b \sin t \\
u\end{array}\right]$ & $\begin{array}{l}(r, u) \in([0,2 \pi] \times R) \text { and } a, b \in R^{+} \text {; the } \\
\text { directrix is an ellipse and the generatrices are } \\
\text { parallel to } z \text {-axis. Different cylinders can be } \\
\text { described taking a regular simple curve as } \\
\text { directrix. }\end{array}$ \\
\hline Cone: & $\mathbf{w}(t, u)=$ & $\left.\begin{array}{c}a u \cos t \\
b u \sin t \\
u\end{array}\right]$ & $\begin{array}{l}(r, u) \in([0,2 \pi] \times R) \text { and } a, b \in R^{+} \text {; the } \\
\text { vertex is placed in } O \text { and the sections } \\
\text { orthogonal to the } z \text {-axis are ellipses } \\
\text { (directrices). Other conic surfaces come from } \\
\text { the different choice of the directrix. }\end{array}$ \\
\hline $\begin{array}{l}\text { Hyperboloid } \\
\text { of one sheet: }\end{array}$ & $\mathbf{w}(t, u)=$ & $\left.\begin{array}{c}a C h u \cos t \\
b C h u \sin t \\
c S h u\end{array}\right]$ & $\begin{array}{l}(r, u) \in([0,2 \pi] \times R) \quad \text { and } \quad a, b, c \in R ; \\
\text { sections orthogonal to the } z \text {-axis are ellipses. }\end{array}$ \\
\hline $\begin{array}{l}\text { Hyperbolic } \\
\text { paraboloid: }\end{array}$ & $\mathbf{w}(t, u)=$ & $\begin{array}{c}u \\
a^{2} t^{2}-b^{2} u^{2}\end{array}$ & $\begin{array}{l}(t, u) \in(R \times R) \text { and } a, b \in R \text {; sections } \\
\text { orthogonal to the } z \text {-axis are hyperbolas; } \\
\text { sections orthogonal to the } x \text { - or } y \text {-axis are } \\
\text { parabolas. }\end{array}$ \\
\hline
\end{tabular}




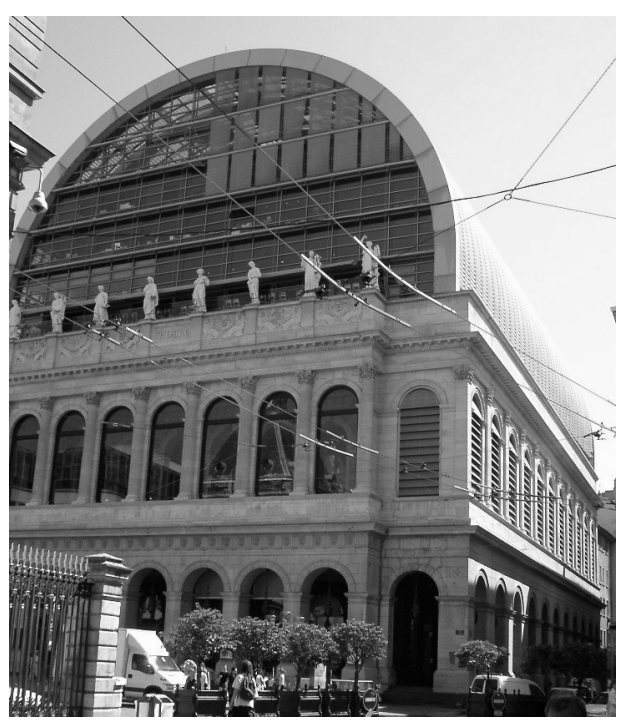

a

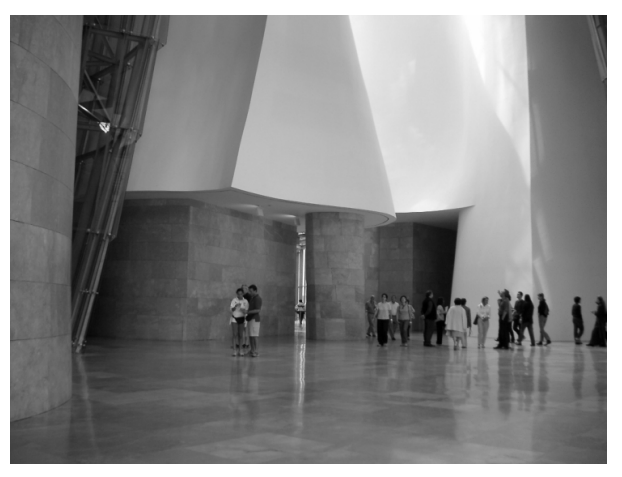

$c$

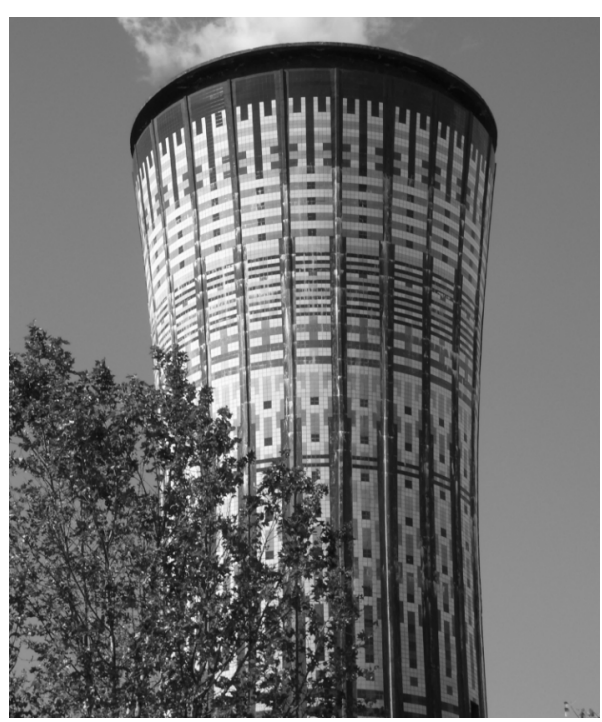

b

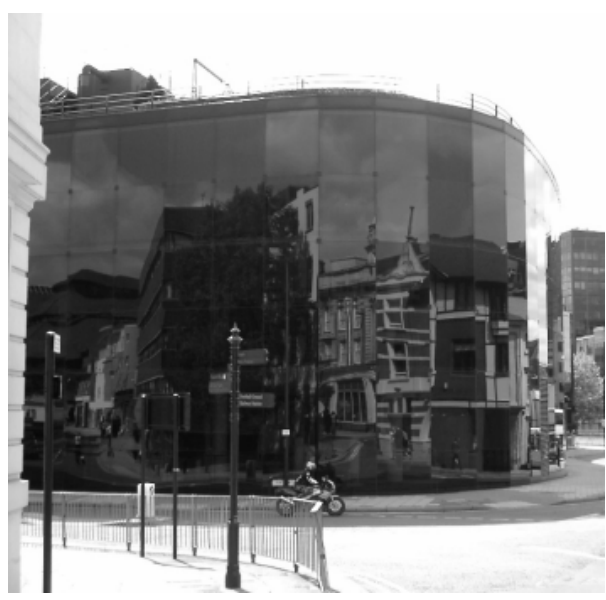

$\mathrm{d}$

Fig. 1. a) Lyon Opera Theatre by J.Nouvel (photo by L. Rossi); b) Cooling tower in Milan (photo by E. Marchetti); c) Guggenheim Museum, Bilbao by F. Gehry (photo by L. Rossi); d)The Willis building, Ipswich, by N. Foster (photo by L. Rossi)

We recall that cylinder, cone, hyperboloid of one sheet and hyperbolic paraboloid are ruled surfaces, that is through each point of them passes at least one straight line that lies entirely in the surface.

Frequently ruled surfaces contain two families of rulings, such as the hyperboloid of one sheet (doubly ruled).

82 E. MARCHETTI and L. Rossi COSTA - Mathematical Elements in Historic and Contemporary Architecture 
The equations given above can be combined and adapted to the geometry of many shapes. Cylindrical, conical and hyperbolic surfaces are recognizable in fig.s $1 \mathrm{a}$ and $1 \mathrm{~b}$ as well in the Philips Pavilion by Le Corbusier [Capanna 2000], in the Rodin Museum in Seoul by KPF and in buildings by Gehry and Foster (figs. 1c and $1 \mathrm{~d})$.

\section{Curves on domes}

Two families of curves become evident from a regular parameterisation of a surface. They are called parameter curves and their equations are obtained by alternatively considering one of the two parameters as constant [Oprea 1997].

In the spherical surface $\mathbf{w}(t, u)=\left[\begin{array}{c}r \sin t \cos u \\ r \sin t \sin u \\ r \cos t\end{array}\right],(r, u) \in([0, \pi] \times[0,2 \pi])$, parallels and meridians are curves obtained by fixing $t$ (u-parameter curve) or $u$ ( $t$ parameter curve) respectively.

In the cylindrical surface $\mathbf{w}(t, u)=\left[\begin{array}{c}a \cos t \\ b \sin t \\ u\end{array}\right],(r, u) \in([0,2 \pi] \times R)$ and $a, b \in R^{+}$,

straight lines and ellipses are obtained with constant values of $t$ or $u$ respectively.

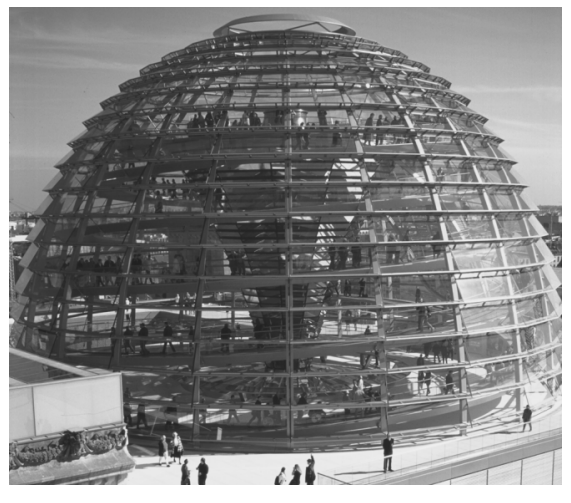

a

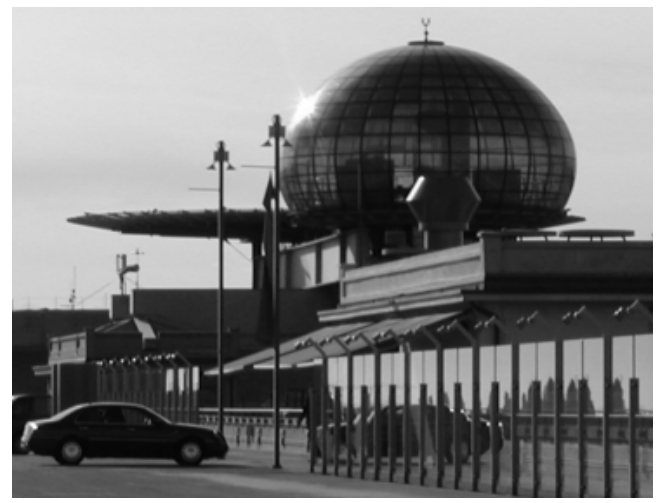

b

Fig. 2. a) The Reichstag's Dome by Norman Foster (photo courtesy of Forster and Partners); b) The "bubble" by Renzo Piano in Turin (photo by K. Williams)

Frequently contemporary architects make evident families of parameter curves in vaults and domes: see for example the Reichstag's dome by Norman Foster in Berlin (fig. 2a) and the bubble of Renzo Piano in Turin (fig. 2b).

We can describe other curves belonging to a surface that are not included in the two families of parameter curves. We mention the well-known cylindrical spiral, 
$\mathbf{v}(t)=\left[\begin{array}{c}r \cos t \\ r \sin t \\ a t\end{array}\right], t \in R, a \in R$, but we can highlight other 3D-spirals developed on different surfaces.

For instance, the curve $\mathbf{v}(t)=\left[\begin{array}{c}r t \cos t \\ r t \sin t \\ r \sqrt{1-t^{2}}\end{array}\right], t \in[0,1]$, belongs to a hemi-sphere (radius $r$ ) and its projection on the $x y$ plane is an arc of Archimedean spiral.

In ancient monuments the spiral appears on many occasions and in different cultural contexts: examples are found in Arabian minarets and in the spire of S.Ivo alla Sapienza by Borromini in Rome.

We prefer here to focus on the use of spirals in contemporary architecture.

Norman Foster frequently uses different spirals in his projects, not only in a decorative sense but also in a functional way [Foster and Partners]: inside the dome of the Reichstag two ramps, starting from two diametrically opposite points of the floor, follow spherical spirals going up towards the top of the hemi-sphere (fig. 2a).

In the New London City Hall the conic ramps encircling the Assembly Chamber take the public from the ground floor to the viewing platform at the top of the building (fig. 3).

We'd like to mention that Foster dealt with interesting questions of optimisation in planning the City Hall. The shape is a deformation of a sphere and its surface is reduced $25 \%$ with respect to the surface of a cube having the same volume. The form was also studied to reduce the energy needs and costs as well for a better use of the sunlight [Foster and Partners].

Analysing the aspects that architects frequently deal with in designing, it becomes more and more evident that Mathematics plays a crucial role in developing an aesthetically attractive and functional construction.

Going back to the geometric aspects, cylindrical spirals appear evident in different way in modern skyscrapers: sometimes by twisting a cube (fig. 4) or the entire building, as in the project by Zaha Hadid for the trade fair area in Milan (see http://www.nuovopolofieramilano.it), other times by rotation of a motif, such as a balcony inside the Jim Mao Tower by Skidmore, Owings and Merrill in Shanghai (see http://www.emporis.com/en/wm/bu/?id=103803).

Other interesting curves can arise from the intersection of two surfaces, [Loria 1930; Loria 1925].

84 E. MARCHETTI and L. Rossi COSTA - Mathematical Elements in Historic and Contemporary Architecture 

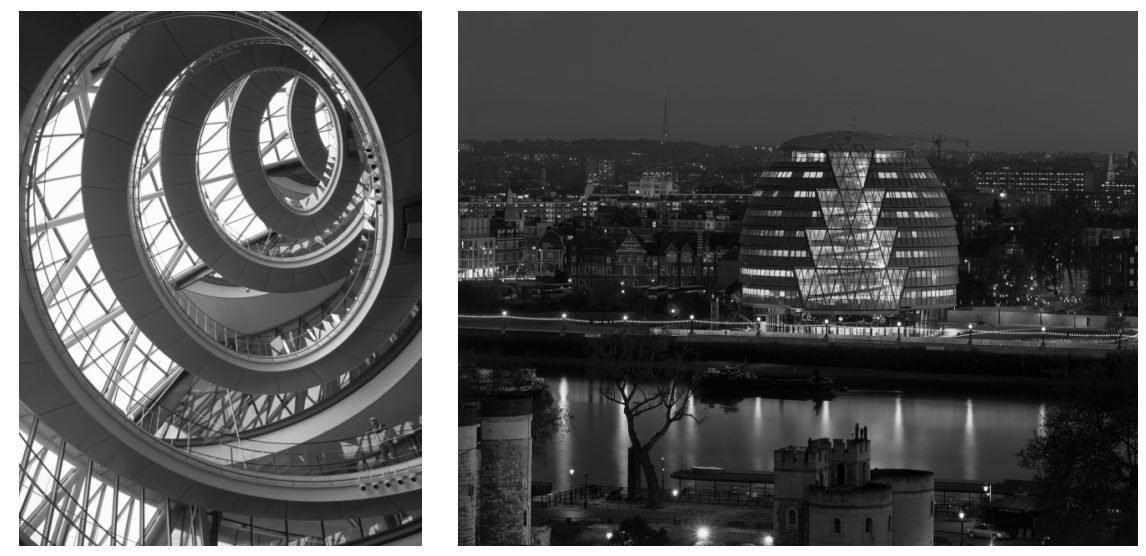

Fig. 3. The conic ramps of London City Hall. Photos courtesy of Foster and Partners

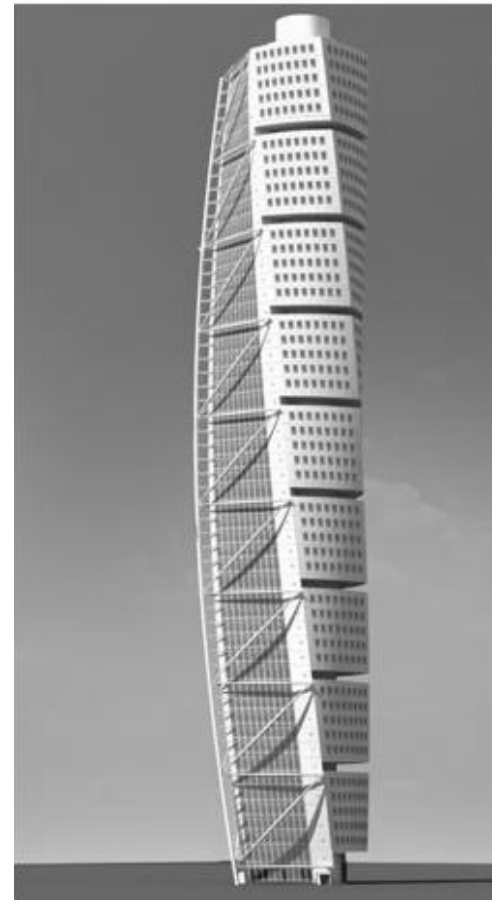

Fig. 4. HBS Malmö - Turning Torso Tower by Santiago Calatrava (photo courtesy of Turning Torso Meetings, http://www.turningtorsomeetings.com/) 
Let us consider the curve belonging to the sphere $\mathbf{w}_{1}(t, u)=\left[\begin{array}{c}r \sin t \cos u \\ r \sin t \sin u \\ r \cos t\end{array}\right]$,

$(r, u) \in([0, \pi] \times[0,2 \pi])$ and to the cylinder

$\mathbf{w}_{2}(t, u)=\left[\begin{array}{c}u \\ \alpha+\beta \sin t \\ \beta \cos t\end{array}\right]$,

$(r, u) \in([0,2 \pi] \times R), \alpha, \beta$ being positive real parameters.

Making the choice $0<\alpha<r / 2, \alpha=\beta, \mathbf{w}_{2}(t, u)$ becomes a cylindrical surface passing through the centre of the sphere. The intersection of the two surfaces is the so-called curve of Roberval, formed by two simple closed curves (fig. 5a).

The choice $0<\alpha<r, \beta=r-\alpha$ gives a cylinder tangent to the sphere. Its intersection with the sphere is called the Hippopede of Eudoxus; it is a closed curve having a double point where the two surfaces are tangent (fig. 5b).

The choice $\alpha=\beta=r / 2$, gives a particular case (limit case of both overmentioned). The intersection is Viviani's curve (fig. 5c).

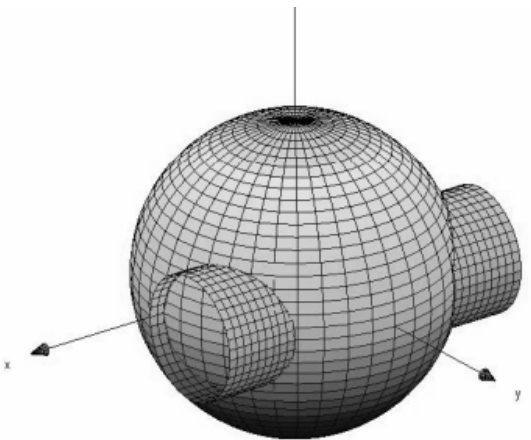

a

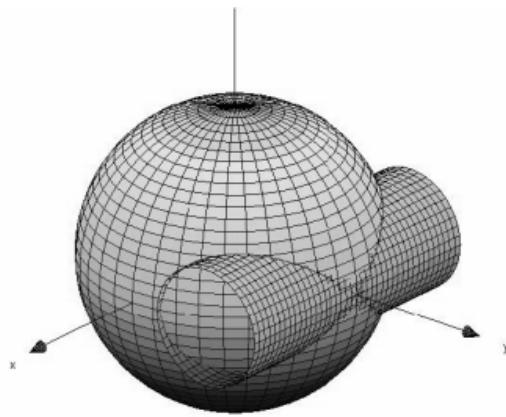

b

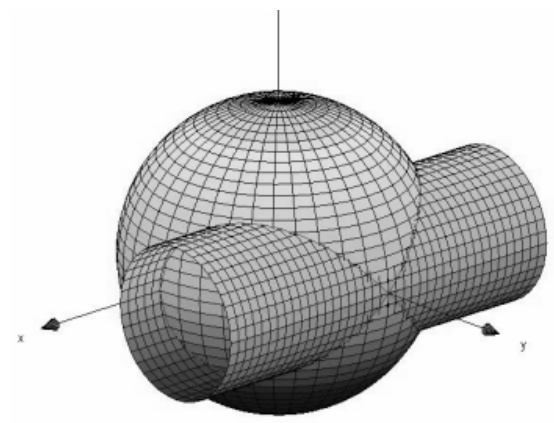

C

Fig. 5. a) Curve of Roberval; b) Hippopede of Eudoxus; c) Viviani's curve. The graphic visualizations are produced using MATLAB 6.5

86 E. MARCHETTI and L. Rossi COSTA - Mathematical Elements in Historic and Contemporary Architecture 
These three curves are related to cutting out windows in domes, as in St. Peter's cathedral in Rome or in S. Lorenzo by Guarino Guarini in Turin.

In 1692 Vicenzo Viviani proposed the problem to construct four windows in a hemispherical vault so that the remainder of the surface can be accurately determined. Viviani's curve arises from the formation of a spherical portion, which he called Vela Quadrabile Fiorentina (quadrable Florentine vault), having rational measure with respect to the square of the radius: cutting out of the sphere surface the four "eyes" selected from two Viviani's curves (fig. 6a), the remaining part (two opposing Vela Quadrabile Fiorentina) has area equal to $8 r^{2}$ [Marchetti and Rossi Costa 2004].

It should be noted that cutting out four equal segments of a sphere, the remaining surface is formed by two traditional sail vaults, whose area is irrational with respect to $r^{2}$ (fig. 6b).

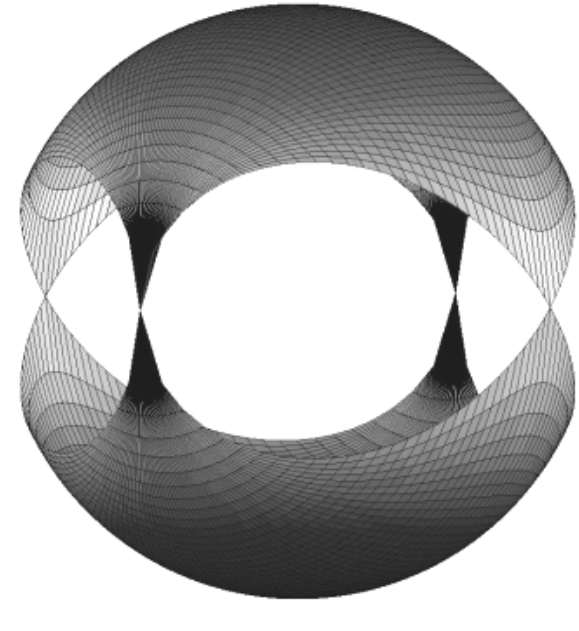

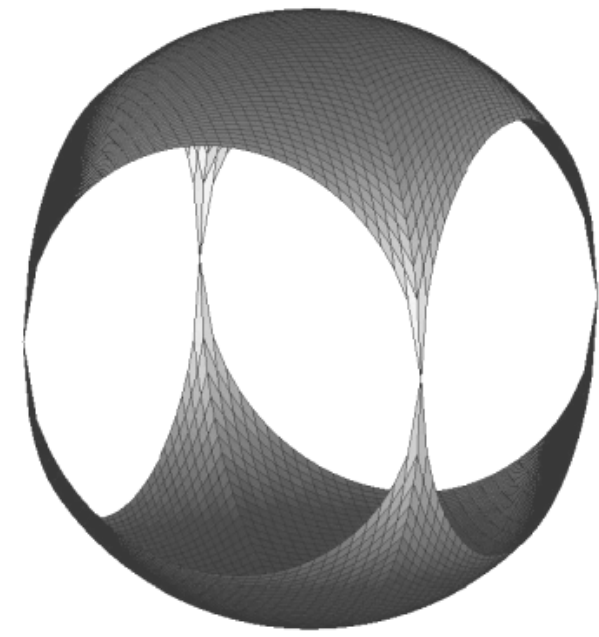

b

Fig. 6. The surfaces formed a) by two Vela Quadrabile Fiorentina; b) by two traditional sail vaults. The graphic visualizations are produced using MATLAB 6.5

The intersections of two semi-cylinders (barrel vaults in Architecture), having orthogonal generatrices,

$$
\mathbf{w}_{1}(t, u)=\left[\begin{array}{c}
u \\
r \cos t \\
r \sin t
\end{array}\right],(t, u) \in([0, \pi] \times R) \text { and } \mathbf{w}_{2}(t, u)=\left[\begin{array}{c}
r \cos t \\
u \\
r \sin t
\end{array}\right],(t, u) \in([0, \pi] \times R),
$$


are two arches of the ellipses represented by the vectors $\mathbf{v}_{1}(t)=\left[\begin{array}{c}r \cos t \\ r \cos t \\ r \sin t\end{array}\right], t \in[0, \pi]$ and $\mathbf{v}_{2}(t)=\left[\begin{array}{c}-r \cos t \\ r \cos t \\ r \sin t\end{array}\right], t \in[0, \pi]$ respectively.

These arches are called ribs or costoloni and they belong to cross vaults as well as to cloister vaults (fig. 7).

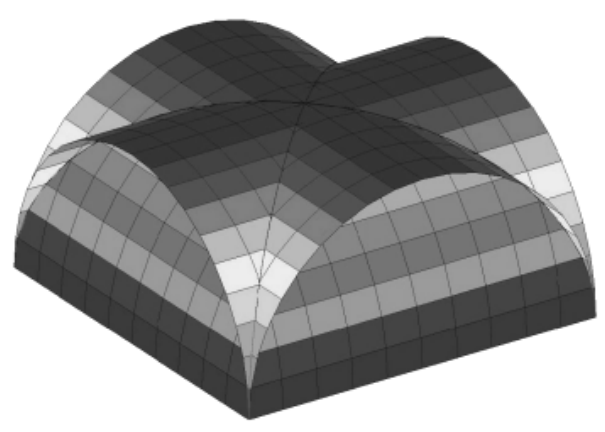

Fig. 7. Ribs in a cross vault. The graphic visualization is produced using MATLAB 6.5

Frequently, domes such as Brunelleschi's dome in Florence or the Mole Antonelliana (fig.8) in Turin are formed by portions of barrel vaults and posed on a polygonal drum; the generatrices are parallel to the polygon sides.

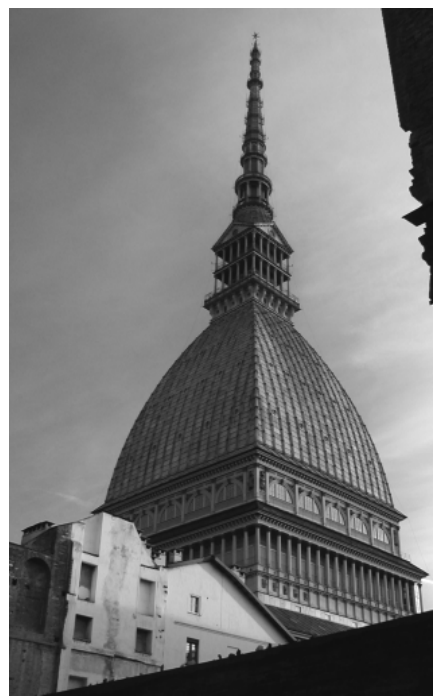

Fig. 8. The Mole Antonelliana, Turin (photo by K. Williams)

88 E. MARCHETTI and L. Rossi COSTA - Mathematical Elements in Historic and Contemporary Architecture 
In Brunelleschi's dome [Battisti 1976] each cylindrical segment is composed of parts of three different cylinders with sections having separated centres, even if very close.

The vertical median section of each segment represents the directrix of the cylindrical surface; it is a polycentric curve formed by three arches of different circles, whose centres belong to the diameter of the circle inscribed in the octagonal basic section. Consequently three arches of different ellipses form the ribs of the dome of S.Maria del Fiore (fig. 9).
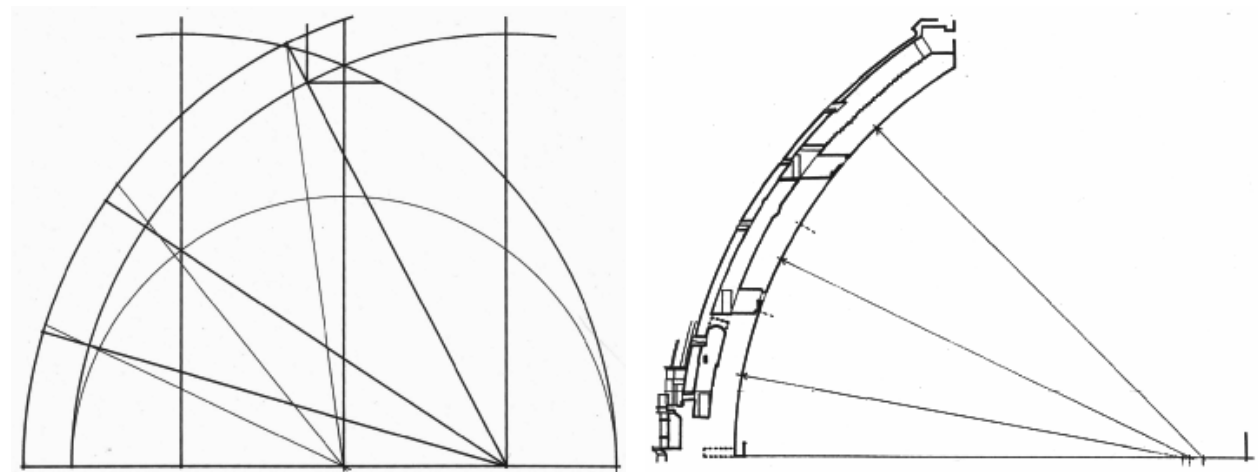

Fig. 9. Sections of the cylindrical dome segments in S.Maria del Fiore by Brunelleschi in Florence, after Battisti 1976

Among many different ancient examples of elliptical and oval domes, we would like to mention three important monuments. The Residenz Church in Würzburg by B. Neumann (1741) is one of the most important Baroque monuments in Germany [Giordano 1999]; the two churches in Rome, S. Carlino alle Quattro Fontane by Borromini and S. Andrea al Quirinale by Bernini (both seventeenth century), are also located very close to each other, so that you can enjoy the elegant architecture of both.

We cannot forget that Gaudì frequently used parabolic domes; naturally the list of citations could be longer but the choice of mentioning Gaudì, among others prominent architects, gives us the opportunity to reaffirm that his works appear to be born by improvisation although he had a strong formation in geometry.

We can collect a lot of examples of quadric surfaces in contemporary buildings.

The use of circular or elliptical cylinders is quite frequent in buildings planned by Mario Botta. Most of them are cut by an oblique plan so that the roof becomes a big round window (see http://www.botta.ch/Page/Recenti_en.php). The light entering through the glass forms a suggestive geometric pattern playing with the courses of bricks or of different stones. The effect is considerable especially in churches such as S. Giovanni Battista in Mogno and the chapel of S. Maria on Monte Tamaro (both in Ticino, Switzerland) and the Cathedral in Évry (France) 
[Lavigne 2001]. The use of a conical surface is evident in the Museum Rodin by Kohn Pedersen Fox Associates (fig. 10).

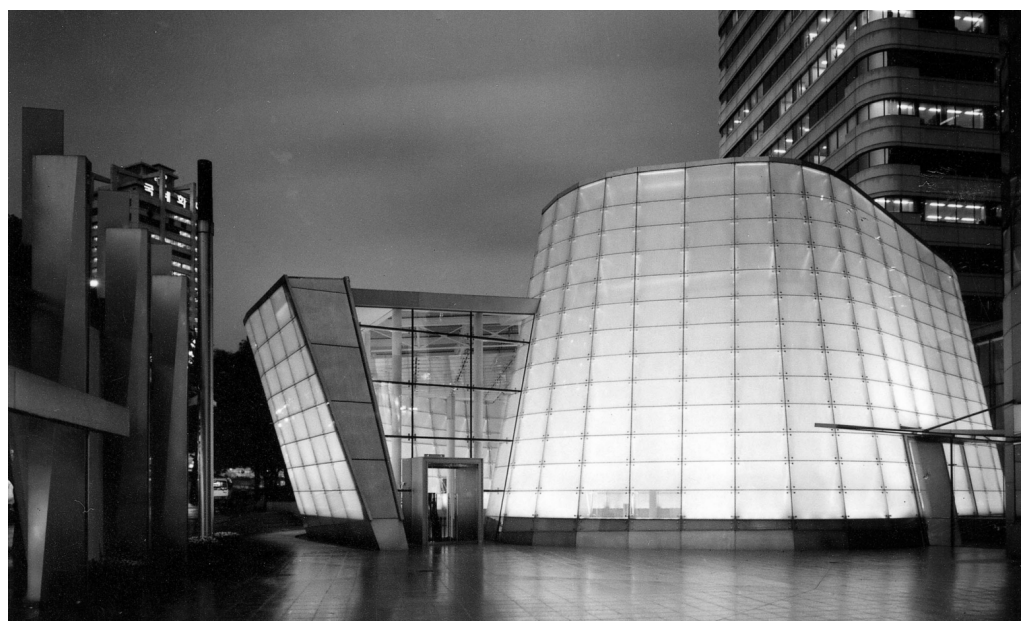

Fig.10. Rodin Museum, Samsung Headquarters Plaza - Seoul (South Korea) by Kohn Pedersen Fox Associates (photo by T. Hursley)

To conclude we like to give attention to the unusual application of spherical elements by Richard Meier in the church of Tor Tre Teste, Rome (fig. 11). Three portions of a sphere, having equal radius and centred on the same line, form the main part of the church Dives in Misericordia. These geometric portions, called sails by Meier himself, are walls and domes at the same time [Meier 1997]. They are self-supporting and give the building an impressive symbolic as well as religious character.

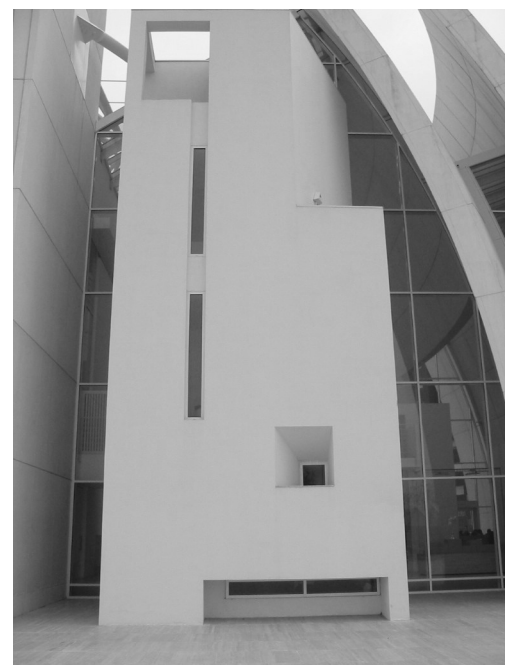

Fig. 11. The Church Tor Tre Teste, Rome (photo A. Geroldi)

90 E. MARCHETTI and L. ROSSI COSTA - Mathematical Elements in Historic and Contemporary Architecture 
The concrete panels (conci) forming the structure are studied with regard to modern environmental impact, so that they have particular qualities. They are not only more resistant but are also designed to maintain their white brilliant colour through the addition of Carrara marble powders and titanium bi-oxide.

\section{Conclusions}

We appreciate this new trend in building, not only because of the sociological, ecological, energetic aspects, but also because this kind of planning makes evident the strong contribution of mathematical modelling. Thus the creations of contemporary architecture are strictly bound up with geometry and with the more sophisticated applications of the techniques of modern mathematics.

\section{Acknowledgment}

The authors wish to thank the following for generous permission to reproduce images: Foster and Partners (figs. 2a, 3a, 3b); Kohn Pederson Fox Associates (fig. 10); HBS Turning Torso Meetings (fig. 4).

\section{Notes}

1. Richard Meier, the famous architect born in the USA (New Jersey) in 1934, commenting on his project for the third Millennium Church, built in Tor Tre Teste (Rome, 1998-2003).

2. $C^{1}(I)$ denotes the vector space of continuous functions with derivative function continuous in the interval $I$; the components of the vector $\mathrm{v}(\mathrm{t})$ belong to this functional space. The interval $I$ may be closed, open or unlimited.

3. The symbol $\times$ means Cartesian product between intervals. The vector product is indicated by the symbol $\wedge$.

\section{References}

BATTISTI, E. 1976. Filippo Brunelleschi. Milan: Electa Editrice.

Capanna, A. 2000. Le Corbusier Padiglione Philips. Turin: Universale di Architettura.

FOSTER AND PARTNERS. http://www.fosterandpartners.com.

Giordano, A. 1999. Cupole, volte e altre superfici. Turin: Utet.

HÖWELER, E. 2004. Skyscraper: Vertical Now. New York: Universe Publishing.

LAVIGNE, E.2000. EVRY La cathédrale de la Résurrection. Paris : Edition du Patrimoine.

LORIA, G. Curve sghembe speciali, Bologna: N. Zanichelli Ed.. . 1930. Curve piane speciali. Milan: U. Hoepli Ed.

MarChetTI, Elena and Luisa Rossi COSTA. 2004. Mathematical and historical investigations on domes and vaults. Pp. 73-80 in the Proceedings of the Dresden International Symposium of Architecture, R. Weber and M. Amann eds. Dresden.

MARIO BOTTA ARCHITETTO. http://www.botta.ch.

MeIER, Richard. The Church of the Year 2000. Pp. 13-23 in Proceedings of Workshop "Materie e Strutture per il Nuovo Millennio", Milan Polytecnic - 25 February 1997, Milan.

OpreA, J. 1997. Differential Geometry and its applications. New York: Prentice Hall. 


\section{About the authors}

Elena Marchetti received her doctorate in Mathematics at the Faculty of Sciences at the Università degli Studi in Milan. She was a researcher of Mathematical Analysis at the Department of Mathematics of the Politecnico of Milan, and since 1988 is an associate professor of Istituzioni di Matematica at the Faculty of Architecture of the Politecnico of Milan. For many years she taught in courses of Mathematical Analysis to engineering students, and since 1988 she has taught Mathematics courses to architecture students. Her research activity is concentrated in the area of Numerical Analysis, principally regarding numerical integration and its applications. She has produced numerous publications in Italian and international scientific journals. Her participation and collaboration in several conferences dedicated to the application of mathematics to architecture has stimulated her interest in this subject. The experience gained through intense years of teaching courses to architecture students has led her to publish some textbooks, one of which regards lines and surfaces and has a multimedia support package, on the production of which she collaborated. She published papers with the aim to connect arts, architecture and mathematics.

Luisa Rossi Costa earned her doctorate in Mathematics in 1970 at Milan University and she attended lectures and courses at Scuola Normale Superiore in Pisa and at Istituto di Alta Matematica in Rome. Since October 1970 she has taught at the Engineering Faculty of the Politecnico of Milan, where she is associate professor of Mathematical Analysis. She first developed her research in Numerical Analysis, on variational problems and on calculating complex eigenvalues. Her interest then changed to Functional Analysis and to solving problems connected with partial differential equations of a parabolic type. She also studied inverse problems in order to determinate an unknown surface, an unknown coefficient in the heat equation and a metric in geophysics, with the purpose to find stable solutions in a suitable functional space. She published several papers on these subjects. She took part in the creation of lessons for a first-level degree in Engineering via the Internet. She also researches subjects regarding teaching methods and the formation of high school students; she collaborates on the e-learning platform M@thonline. Following a continuing interest in art and architecture, and believing that mathematics contains a strong component of beauty, she tries to connect these apparently different fields. She published papers connected to this aim. 